NOTAS 


\title{
LA CUESTIÓN LINGÜÍSTICA EN LA SENTENCIA DEL TRIBUNAL CONSTITUCIONAL SOBRE EL ESTATUTO DE AUTONOMÍA DE CATALUÑA
}

\author{
ANGEL LUIS ALONSO DE ANTONIO \\ Profesor Titular de Derecho Constitucional \\ Universidad Complutense de Madrid
}
SUMARIO
I. Introducción
II. La referencia inconstitucional
III. El deber de conocimiento del catalán
IV. El catalán y la educación
V. El uso del catalán ante órganos públicos esta- tales
VI. La utilización de las lenguas en las relaciones comerciales
VII. El uso del catalán por las instituciones públi- cas catalanas
VIII. El catalán y los funcionarios de la Adminis- tración de Justicia

\section{INTRODUCCIÓN}

Mediante la sentencia 31/2010, de 28 de junio, el Tribunal Constitucional resolvió el recurso de inconstitucionalidad interpuesto por noventa y nueve diputados del Grupo Parlamentario Popular del Congreso contra diversos preceptos de la Ley Orgánica 6/2006, de 19 de julio, de reforma del Estatuto de Autonomía de Cataluña.

Uno de los puntos a los que el Tribunal Constitucional dedica mayor atención es al tema lingüístico. Debe apuntarse que el Estatuto de Cataluña de 2006 recoge los principios básicos ya contenidos en la Ley 1/1998, de 7 de enero, de Política Lingüística. Ha de reconocerse que esta cuestión es especialmente sensible ${ }^{1}$ en Cataluña por la singula-

1 En el mismo sentido Tornos Mas, J., «El Estatuto de Autonomía de Cataluña y el Estado autonómico, tras la sentencia del Tribunal Constitucional 31/2010», en El Cronista del Estado Social y Democrático de De- 
ridad de las lenguas que se hablan en ella. Baste recordar, en este sentido, la reciente Ley 35/2010, de 1 de octubre, del occitano, aranés en Arán, que reconoce según su artículo 4 a la lengua propia de Arán como lengua oficial en Cataluña. No es preciso recordar que el tema lingüístico viene dando origen a posturas cada vez más viscerales y la aplicación de determinadas normas jurídicas tiene consecuencias difícilmente entendibles. Es lógico que el tema de las lenguas sea un asunto preferente en la STC 31/2010. Cosa distinta es que los pronunciamientos del Tribunal merezcan una valoración global positiva o más bien crítica. Como idea inicial, debe decirse que la postura del Tribunal ha sido salomónica. Ha declarado inconstitucional, y por tanto nulo, un extremo importante pero en otros, no menos importantes, se ha decantado por una sentencia interpretativa que no despeja las dudas ni resuelve los problemas y lo ha hecho además con excesiva profusión lo que ha suscitado recelos en ciertos autores. Así, para Muñoz Machado el Tribunal Constitucional ha utilizado el recurso de la "interpretación conforme" de modo «manifiestamente abusivo, forzando la literalidad de algunos preceptos, la voluntad del legislador, el espíritu y la sistemática de la norma, y sustituyéndola por su propio arbitrio. No interpretando la norma, sino más bien creándola al margen del espíritu y de la letra de los preceptos impugnados» ${ }^{2}$.

\section{LA REFERENCIA INCONSTITUCIONAL}

El Tribunal Constitucional declara inconstitucional la referencia «y preferente» del artículo 6.1. Ese artículo decía originariamente que «la lengua propia de Cataluña es el catalán. Como tal, el catalán es la lengua de uso normal y preferente de las administraciones públicas y de los medios de comunicación públicos de Cataluña, y es también la lengua normalmente utilizada como vehicular y de aprendizaje en la enseñanza». La normalidad en el uso del catalán es una cuestión fáctica que el EAC se limita a constatar. El problema es que después el artículo de referencia incluye una mención derivada de una decisión política, el uso preferente del catalán por las administraciones públicas y los medios de comunicación públicos, lo que implica, en palabras de Marc Carrillo, una «primacía de una lengua sobre otra, estableciendo un uso prioritario de una de ellas» ${ }^{3}$. Con buen criterio, aunque para Tornos Mas tenga escasa relevancia práctica ${ }^{4}$ el Tribunal

recho, núm. 15, 2010, pág. 22 y MuRO BAS, X., «Valoración de los aspectos relativos a la lengua en la sentencia de 28 de junio de 2010 sobre el Estatuto de Autonomía de Cataluña», en Revista Catalana de dret públic, Especial Sentencia sobre el Estatuto, 2010. Utilizo la versión digital traducida al castellano, pág. 1. De «tema delicado» habla De la Cuadra-Salcedo Fernández del Castillo, T. «Paisaje después de la batalla. La sentencia del TC sobre el Estatuto de Cataluña», en Claves de Razón Práctica, núm. 206, 2010, pág. 23.

2 MuÑoz Machado, S., «Dentro de los términos de la presente Constitución», en El Cronista del Estado Social y Democrático de Derecho, núm. 15, 2010, pág. 6. En el mismo sentido, el TC «asume una lectura tan forzada de la dicción literal de la norma que genera inseguridad jurídica», PLA BorX, A.M., «El régimen lingüístico en la STC 31/2010, de 28 de junio», en Revista catalana de pret públic. Especial Sentencia sobre el Estatuto, 2010. Utilizo la traducción castellana en la versión digital, pág. 1. De «carácter confuso» habla PONS PARERA, E., «La lengua (en la sentencia de 28 de junio de 2010)», en Revista catalana de dret públic. Especial Sentencia sobre el Estatuto, 2010. Utilizo la traducción castellana en la versión digital, pág. 2.

3 Carrillo, M., «Después de la sentencia, un Estatuto desactivado», en El Cronista del estado Social y Democrático de Derecho, núm. 15, pág. 32.

4 Tornos Mas, J., op. cit., pág. 22. 
Constitucional declara inconstitucional esa alusión porque aquí no se trata de la utilización individual de una lengua u otra, que es una decisión personal, sino de la vinculación de los poderes públicos a una prescripción normativa que choca con la cooficialidad en Cataluña de las dos lenguas, castellano y catalán, y desconoce el carácter del castellano como única lengua oficial en todo el territorio nacional. Si el castellano es lengua oficial en Cataluña no puede estar en desventaja ante los poderes públicos catalanes y ello porque, como apunta el Tribunal Constitucional «toda lengua oficial es, por tanto - también allí donde comparte esa cualidad con otra lengua española-, lengua de uso normal por y ante el poder público. También, en consecuencia, lo es el castellano por y ante las Administraciones públicas catalanas, que, como el poder público estatal en Cataluña, no pueden tener preferencias por ninguna de las dos lenguas oficiales» [FJ 14 a)]. Se reitera de este modo la consolidada doctrina del Tribunal Constitucional que ya declaró en su día que «en los territorios dotados de un estatuto de cooficialidad lingüística, el uso por los particulares de cualquier lengua oficial tiene efectivamente plena validez jurídica en las relaciones que mantengan con cualquier poder público radicado en dicho territorio, siendo el derecho de las personas al uso de una lengua oficial un derecho fundado en la Constitución y el respectivo Estatuto de Autonomía» (STC 82/1986, de 26 de junio. FJ 3). El Tribunal Constitucional, como se apuntó, declara inconstitucional y anula esa referencia del artículo 6.1 porque, como apunta Francesc de Carreras, «ello supondría la primacía de una lengua sobre otra, es decir, un trato privilegiado» ${ }^{5}$.

\section{EL DEBER DE CONOCIMIENTO DEL CATALÁN}

A diferencia de lo que acaba de apuntarse, es decir, la declaración de inconstitucionalidad de un precepto, el Tribunal Constitucional utiliza un criterio interpretativo en relación al deber de conocer el catalán que se recoge en el artículo 6.2, según Marc Carrillo «partiendo de la presunción de conocimiento del catalán adquirida a través de la escuela» ${ }^{6}$. Ese artículo dice que «el catalán es la lengua oficial de Cataluña. También lo es el castellano, que es la lengua oficial del estado español. Todas las personas tienen derecho a utilizar las dos lenguas oficiales y los ciudadanos de Cataluña el derecho y el deber de conocerlas. Los poderes públicos de Cataluña deben establecer las medidas necesarias para facilitar el ejercicio de estos derechos y el cumplimiento de este deber. De acuerdo con lo dispuesto en el artículo 32, no puede haber discriminación por el uso de una u otra lengua». En cuanto a este artículo hay que comenzar señalando la inexistencia de un deber constitucional de conocer las lenguas autonómicas cooficiales, como ya apuntó el Tribunal Constitucional en STC 82/1986, de 26 de junio, FJ 3 y reitera ahora en el FJ 14 b). Sin embargo, ello no quiere decir que haya una prohibición constitucional de incorporar esa obligación por vía estatutaria, como se dice en el citado FJ 14 b). El Estatuto de Autonomía de una Comunidad Autónoma con lengua propia puede incluir este deber que no será excluyente ni tan siquiera de índole superior al deber general, este sí con-

5 Carreras Serra, F. DE, «¿Es constitucional el Estatuto de Cataluña?. El Estado de las autonomías tras la sentencia del TC», en Claves de Razón Práctica, núm. 206, pág.18.

6 Carrillo, M., op. cit., pág. 32. 
templado en la Constitución, de conocer el castellano (art. 3.1), aunque el Tribunal Constitucional consideró en su S 74/1987, de 25 de mayo, en relación con el artículo 520.2.e) de la Ley de Enjuiciamiento Criminal (derecho a intérprete en actuaciones policiales y judiciales) que ese deber «hace suponer que ese conocimiento existe en la realidad, pero tal presunción puede quedar desvirtuada cuando el detenido o preso alega verosímilmente su ignorancia o conocimiento insuficiente o esta circunstancia se pone de manifiesto en el transcurso de las actuaciones policiales» (FJ 3), de forma que «el derecho de toda persona, extranjera o española, que desconozca el castellano a usar de intérprete en sus declaraciones ante la Policía, deriva... directamente de la Constitución y no exige para su ejercicio una configuración legislativa, aunque ésta puede ser conveniente para su mayor eficacia» FJ 4). Quiere decirse, por tanto, que aunque el Estatuto catalán incorpore esta previsión ello no supone que pueda haber menoscabo en la utilización de la única lengua oficial de todo el Estado, el castellano, ni implica que el Estado deba hacer dejación de una obligación de tutela de esta lengua oficial. Parece olvidar, pues, el Tribunal Constitucional su doctrina recogida en la S 82/1986, de 26 de junio, cuando señala que «no ha perderse de vista, por otra parte, que no cabe contraponer el castellano en cuanto lengua española oficial del Estado, y las “demás lenguas españolas” en cuanto cooficiales en las distintas Comunidades, como asuntos privativos respectivamente del Estado en sentido estricto y de las Comunidades Autónomas individualmente consideradas. Como añade el art. 3.3 de la Constitución, "la riqueza de las distintas modalidades lingüísticas de España es un patrimonio cultural que será objeto de especial respeto y protección"; respeto y protección que por definición incumben al Estado en sentido estricto y también a las Comunidades Autónomas, algunos de cuyos Estatutos de Autonomía les encomiendan, por lo demás, expresamente, garantizar el uso de ambas lenguas oficiales y adoptar los medios necesarios para asegurar su conocimiento» (FJ 4).

El Tribunal Constitucional intenta diferenciar jurídicamente el alcance del deber constitucional de conocer el castellano y el deber estatutario de conocer el catalán. Y lo hace con remisión inexacta a su propia doctrina. Así, en el FJ 14 b) se cita el FJ 2 de la STC 82/1986, de 26 de junio, donde considera el deber de conocer el castellano como «individualizado y exigible». Sin embargo, hay que decir que en ese FJ no aparece tal mención. Algo parecido sí se recoge en el FJ 3 de la citada STC cuando se dice que «sólo del castellano se establece constitucionalmente un deber individualizado de conocimiento, y con él, la presunción de que todos los españoles lo conocen». Sin embargo, el Tribunal Constitucional se refiere ahora al deber de conocer el catalán vinculándole a una obligación de los poderes públicos «para que adopten las medidas necesarias para facilitar... el cumplimiento de ese deber...» [FJ 14 b)], después de señalar en el mismo FJ, con carácter general, la «procedencia de que el legislador pueda adoptar, en su caso, las adecuadas y proporcionadas medidas de política lingüística tendentes a corregir, de existir, situaciones históricas de desequilibrio de una de las lenguas oficiales respecto de la otra, subsanando así la posición secundaria o de postergación que alguna de ellas pudiera tener». Esa frase es la llave para que desde los partidos nacionalistas catalanes se continúe con la política de implantación del catalán como lengua preponderante en Cataluña en detrimento del castellano que puede verse relegado a un papel secundario. El Tribunal Constitucional, de manera un tanto confusa y con errores materiales como se ha señalado, «de una forma que parece ir más allá de su sentido 
inmediato ${ }^{7}$ interpreta el artículo 6.2 EAC en el sentido de que se trata de «un deber individualizado y exigible» de conocimiento del catalán, es decir, de un deber de naturaleza distinta al que tiene por objeto al castellano de acuerdo al art. 3.1 CE» [FJ 14.b)]. Entendida de esta extraña manera la obligación de conocer una lengua u otra, y toda vez que las competencias en relación a la normativa de las lenguas autonómicas se dejan en manos de las Comunidades Autónomas, la conclusión va a ser el retroceso en la utilización pública del castellano en favor de la lengua vernácula. Eso no lo quiso el constituyente ni el propio Tribunal Constitucional en sus primeros momentos, como se ha visto. Ahora, sin embargo, la postura del Tribunal es otra porque el deber de conocimiento del catalán se interpreta en el sentido «no de un deber generalizado para todos los ciudadanos de Cataluña, sino de la imposición de un deber individual y de obligado cumplimiento que tiene su lugar específico y propio en el ámbito de la educación, según resulta del art. 35.2 EAC, y en el de las relaciones de sujeción especial que vinculan a la Administración catalana con sus funcionarios, obligados a dar satisfacción al derecho de opción lingüística reconocido en el art. 33.1 EAC» [FJ 14b)].

\section{EL CATALÁN Y LA EDUCACIÓN}

Lo que acaba de apuntarse es extraordinariamente importante, de forma destacada por lo que se refiere a la educación porque este pronunciamiento del Tribunal Constitucional consagra lo que viene sucediendo desde hace años, el cuasi monopolio del catalán como lengua vehicular en la enseñanza, algo, por lo demás, que se recoge en el artículo 35 del Estatuto de Autonomía cuando señala en el apartado 1 que «todas las personas tienen derecho a recibir la enseñanza en catalán, de acuerdo con lo establecido por el presente Estatuto. El catalán debe utilizarse normalmente como lengua vehicular y de aprendizaje en la enseñanza universitaria y en la no universitaria». El segundo apartado comienza señalando que «los alumnos tienen derecho a recibir la enseñanza en catalán en la enseñanza universitaria». De nuevo se suscita el debate sobre el alcance de la cooficialidad de las lenguas en una Comunidad Autónoma, en este caso, en el tema de la enseñanza. En este punto el Tribunal Constitucional no ha estado a la altura de las circunstancias y con una decisión meramente interpretativa no resuelve el problema sino que consolida una situación que no es nueva, el predominio del catalán en la enseñanza. Después de recordar con profusión sus sentencias donde se defiende el uso de las dos lenguas en la enseñanza sin que pueda haber menoscabo del castellano al ser lengua oficial de todo el Estado, el Tribunal Constitucional interpreta que la ausencia de la mención del castellano en esos párrafos del artículo 35 no obedece «a un propósito deliberado de exclusión» (FJ 24), y salva la constitucionalidad del artículo señalando que puede interpretarse «en el sentido de que no impiden el libre y eficaz ejercicio del derecho a recibir la enseñanza en castellano como lengua vehicular y de aprendizaje en la enseñanza» (FJ 24). La postura del Tribunal es de una ingenuidad lamentable, dejando a la interpretación futura de los gestores públicos de la enseñanza en Cataluña la utilización de una u

7 De la Cuadra-Salcedo Fernández del Castillo, T., op. cit., pág. 24. 
otra lengua, en este caso, básicamente de una, el catalán. No se puede limitar el Tribunal a señalar que la ausencia de una mención expresa al castellano en el artículo de referencia no impide su utilización. Evidentemente que no lo impide porque no puede hacerlo porque desconocería el carácter oficial del castellano también en Cataluña. El problema es que ese artículo, que Carreras considera que debiera haber sido declarado inconstitucio$\mathrm{nal}^{8}$ no garantiza, sino más bien al contrario, que los ciudadanos puedan recibir enseñanza en castellano y el Tribunal Constitucional al limitarse a interpretarlo de forma tan cicatera no contribuye a defender al castellano como lengua ordinaria en la enseñanza ${ }^{9}$ sino todo lo contrario, le condena a ser una lengua residual sin apenas implantación en las escuelas catalanas, lo contrario de lo que ordena el Tribunal Supremo en las SS 6629/2010 y 6632/2010 de la Sección $4^{\text {a }}$ de la Sala de lo Contencioso Administrativo sobre la consideración del castellano como lengua vehicular en el enseñanza en Cataluña.

\section{EL USO DEL CATALÁN ANTE ÓRGANOS PÚBLICOS ESTATALES}

El Tribunal Constitucional también salva con un criterio interpretativo la constitucionalidad del artículo 33.5 EAC según el cual «los ciudadanos de Cataluña tienen el derecho a relacionarse por escrito en catalán con los órganos constitucionales y con los órganos jurisdiccionales de ámbito estatal, de acuerdo con el procedimiento establecido por la legislación correspondiente. Estas instituciones deben atender y deben tramitar los escritos presentados en catalán que tendrán, en todo caso, plena eficacia jurídica». Aquí el Tribunal se limita a remitir el asunto al legislador estatal cuando señala que «la existencia o no de eficacia jurídica de los escritos presentados en catalán a dichos órganos y, en su caso, el grado de ésta ha de ser establecido con entera libertad, dentro de los límites constitucionales (art. 3.1 CE), por el legislador estatal competente» (FJ 21).

No es aceptable que un Estatuto de Autonomía establezca obligaciones de este tipo a un órgano no radicado en su territorio, máxime cuando se trata de órganos nacionales cuya lengua de trabajo debe ser la única que tiene carácter oficial en todo el Estado, es decir, el castellano. Téngase en cuenta que según la STC 82/1986, de 26 de junio, del artículo 2.3 CE «se sigue que la consecuente cooficialidad lo es con respecto a todos los poderes públicos radicados en el territorio autonómico, sin exclusión de los órganos dependientes de la Administración central y de otras instituciones estatales en sentido estricto, siendo, por tanto, el criterio delimitador de la oficialidad del castellano y de la cooficialidad de otras lenguas españolas el territorio, independientemente del carácter estatal (en sentido estricto), autonómico o local de los distintos poderes públicos» (FJ 2). A sensu contrario, los poderes públicos radicados fuera del territorio autonómico no están vinculados por el carácter oficial de le lengua de una determinada Comunidad Autónoma. En este sentido, el titular de un órgano del Estado no radicado en Cataluña no tiene ninguna obligación de conocer el catalán y por tanto el deber impuesto por el artículo 33.5 EAC puede resultar inútil. La legislación estatal de desarrollo debería dejar sin contenido una obligación como la que se comenta.

8 Carreras Serra, F. De, op. cit., pág. 18.

9 Algo que parece «grave» a Muro BAs, X., op. cit., pág. 4. 


\section{LA UTILIZACIÓN DE LAS LENGUAS EN LAS RELACIONES COMERCIALES}

Merece destacarse la interpretación del Tribunal Constitucional sobre el artículo 34 EAC según el cual «todas las personas tienen derecho a ser atendidas oralmente y por escrito en la lengua oficial que elijan en su condición de usuarios o consumidores de bienes, productos y servicios. Las entidades, las empresas y los establecimientos abiertos al público en Cataluña quedan sujetos al deber de disponibilidad lingüística en los términos establecidos por ley». Se cuestionaba la constitucionalidad del último inciso del artículo, el deber de disponibilidad lingüística por parte de las empresas. El Tribunal Constitucional salva la constitucionalidad del inciso alegando que esa disponibilidad es necesaria consecuencia del derecho de opción lingüística, que no puede significar la imposición a los establecimientos de un uso de cualquiera de las dos lenguas oficiales de modo general en las relaciones privadas y que, en todo caso, como el artículo remite a una ley de desarrollo será cuando se establezcan allí los términos de ese deber de disponibilidad cuando «quepa esperar de nosotros (el TC) un pronunciamiento jurisdiccional sobre la adecuación constitucional de los concretos términos en los que se articule dicho deber» (FJ 22). Es decir, aplaza en el tiempo la recta resolución del tema que se plantea sin comprometerse ahora dando por zanjado un asunto que afecta a las relaciones personales diarias en el ámbito mercantil. Ese desarrollo se ha producido mediante la Ley 22/2010, de 20 de julio, de Código de Consumo de Cataluña, que recoge una regulación escasamente respetuosa con el pronunciamiento del Tribunal Constitucional porque, aunque en su artículo 128.1 señala que «las personas consumidoras, en sus relaciones de consumo, tiene derecho, de acuerdo con lo establecido por el Estatuto de Autonomía y la legislación aplicable en materia lingüística, a ser atendidas oralmente y por escrito en la lengua oficial que escojan», añade en el punto 2 del mismo artículo que «las personas consumidoras, sin perjuicio del respeto pleno al deber de disponibilidad lingüística, tienen derecho a recibir en catalán» una serie de informaciones, datos, cláusulas contractuales etc. Sólo se indica el derecho a recibir esa información en catalán, no en castellano o no también en castellano. En este sentido y como «consumidores» de cultura hay que señalar la aprobación de la Ley 20/2010, de 7 de julio, del cine, que tiene como uno de sus objetivos aumentar la presencia del catalán en las pantallas de Cataluña.

\section{EL USO DEL CATALÁN POR LAS INSTITUCIONES PÚBLICAS CATALANAS}

El Tribunal Constitucional interpreta en el FJ 23 el artículo 50.5 EAC ( «La Generalitat, la Administración local y las demás corporaciones públicas de Cataluña, las instituciones y las empresas que dependen de las mismas y los concesionarios de sus servicios deben utilizar el catalán en sus actuaciones internas y en la relación entre ellos. También deben utilizarlo en las comunicaciones y las notificaciones dirigidas a personas físicas o jurídicas residentes en Cataluña, sin perjuicio del derecho de los ciudadanos a recibirlas en castellano si lo piden») en el sentido de que ha de referirse a las funciones públicas que pueden ejercer las instituciones y empresas a las que se refiere el artículo. En este orden, 
aunque reconoce que sólo los particulares son titulares del derecho de opción lingüística, el artículo puede ser constitucional si se interpreta «en el sentido de que, en el marco de la política de fomento y difusión del catalán, las entidades públicas, instituciones y empresas a las que el precepto se refiere, pueden utilizar la lengua catalana con normalidad, sin perjuicio de poder utilizar también con normalidad el castellano, en sus relaciones internas, en las relaciones entre ellas y en sus comunicaciones con los particulares, siempre que arbitren los mecanismos pertinentes para que el derecho de los ciudadanos a recibir tales comunicaciones en castellano pueda hacerse efectivo sin formalidades ni condiciones que redunden en ellos en una carga u obligación que les constituya en la posición de sujeto activo en sus relaciones con la Administración pública». De nuevo el Tribunal Constitucional es generoso a la hora de interpretar la buena voluntad del legislador autonómico porque, efectivamente, es claro que en el marco a que se refiere el artículo se puede utilizar el castellano pero lo que sucede es que el artículo sólo establece la obligación de usar el catalán y eso es lo que el Tribunal debería haber declarado inconstitucional.

\section{EL CATALÁN Y LOS FUNCIONARIOS DE LA ADMINISTRACIÓN DE JUSTICIA}

Cabe señalar, por último, que según el artículo 33.3 EAC «el personal al servicio de la Administración de Justicia, para prestar sus servicios en Cataluña, deben acreditar, en la forma establecida en las leyes, que tienen un nivel de conocimiento adecuado y suficiente de las lenguas oficiales, que los hace aptos para ejercer las funciones propias de su cargo o su puesto de trabajo» y que en el artículo 102, de forma un tanto reiterativa, se establece la misma condición respecto «del personal judicial y del resto del personal al servicio de la Administración de Justicia en Cataluña». Resulta una exigencia que debe ponerse en íntima relación con el derecho de opción lingüística de los ciudadanos en sus relaciones con los poderes públicos (art. 33.1 EAC) pero que no deja de tener cierto atisbo de discriminación respecto a los integrantes del poder judicial que al no tener un conocimiento adecuado de una lengua oficial sólo en una Comunidad Autónoma no puedan ejercer allí su función mientras que los catalanoparlantes, evidentemente, pueden desarrollar su trabajo en cualquier parte del territorio nacional por su conocimiento del castellano. El Tribunal Constitucional no ve tacha de inconstitucionalidad en el precepto (FF JJ 21 y 51 ).

Como resumen, puede decirse que las decisiones del Tribunal Constitucional en el terreno de la lengua han sido escasamente respetuosas con el castellano como única lengua oficial del Estado, que no se han querido resolver en el fondo las cuestiones prácticas, como la enseñanza, que se suscitan a diario y por la vía, ingenua a veces, de la interpretación de los artículos recurridos se abre la puerta a unas decisiones políticas que pueden poner en peligro la igualdad de derechos de los ciudadanos de Cataluña según la lengua que tengan de uso común. 
TITLE: The linguistic question in the Constitucional Court on the Statute of the Autonomy of Catalonia.

ABSTRACT: In the S 31/2010, June 28», the Constitutional Court examines the linguistic regulation in the new Statute of the Autonomy of Catalonia annulment a subsection of a single item but to abuse the interpretative criterion the constitutionality of several concepts to what was the Constitutional Court nated in respectives bases

Resumen: En la S 31/2010, de 28 de junio, el Tribunal Constitucional analiza la regulación lingüística en el nuevo Estatuto de Autonomía dd Cataluña anulando un inciso de un único artículo pero abusando del criterio interpretativo condicionando la constitucionalidad de varios preceptos a lo que el Tribunal Constitucional señala en los respectivos fundamentos jurídicos.

KeY wORDs: The linguistic cooficiality. Catalán. Spanish. Vehicular language. Linguistic availability. Preferential use. Duty to know. Teaching.

Palabras Clave: Cooficialidad lingüistica. Catalán. Castellano. Lengua vehicular. Disponibilidad lingüística. Uso preferente. Deber de conocer. Enseñanza.

FECHA DE RECEPCIÓN: 6.01.2010. FECHA DE ACEPTACIÓN: 26.01.2011 
